\title{
REESTRUTURAÇÃO PRODUTIVA, TRABALHO E TRANSFORMAÇÕES NO ESPAÇO METROPOLITANO DE FORTALEZA
}

\author{
PRODUCTIVE RESTRUCTURING, LABOR, AND TRANSFORMATIONS IN THE \\ METROPOLITAN SPACE OF FORTALEZA
}

\section{REESTRUCTURACIÓN PRODUCTIVA, TRABAJO Y TRANSFORMACIONES EN EL ESPACIO METROPOLITANO DE FORTALEZA}

\author{
Alexsandra Maria Vieira Muniz - Universidade Federal do Ceará - Fortaleza - Ceará - Brasil \\ geoalexsandra@ufc.br \\ José Borzacchiello da Silva - Universidade Federal do Ceará - Fortaleza - Ceará - Brasil \\ borza@secrel.com.br \\ Maria Clélia Lustosa Costa - Universidade Federal do Ceará - Fortaleza - Ceará - Brasil \\ clelialustosa@gmail.com
}

\section{Resumo}

Diante da reestruturação produtiva e espacial em curso, a Região Metropolitana de Fortaleza (RMF) vivencia a substituição de formas e a diversificação de suas funções. 0 estabelecimento de distritos industriais e conjuntos habitacionais tem resultado na complexidade da estrutura urbana da metrópole com alterações no arranjo socioespacial. Fortaleza, ao contrário de perder funções, reforça sua capacidade de comando, devido aos novos papéis assumidos pelos municípios da RMF na divisão social e técnica do trabalho. No entanto, estes municípios continuam dependentes do abastecimento e suprimento de serviços da capital que se especializa no terciário, aumentando sua força polarizadora e área de influência. As políticas de incentivo ao turismo, aos negócios imobiliários, ao agronegócio e à expansão da indústria no Ceará produzem mudanças na estrutura do emprego e, no mercado de trabalho e, por conseguinte, na metrópole. Este artigo analisa os impactos da reestruturação sobre o espaço metropolitano de Fortaleza e suas implicações no perfil da força de trabalho e na mobilidade espacial. Evidencia o impulso e redimensionamento da indústria na RMF e a consequente expansão de sua zona de influência para outros estados e para o espaço transnacional, bem como favorece o surgimento de novas centralidades.

Palavras-chave: Reestruturação produtiva e espacial, mercado de trabalho, divisão interna e internacional do trabalho, mobilidade populacional.

\begin{abstract}
In the face of the ongoing process of productive and spatial restructuring, the Metropolitan Region of Fortaleza (RMF) experiments the substitution of forms and the diversification of its functions. The creation of industrial districts and large housing projects has led to a complex form of the urban structure in the metropolis, with changes in the socio-spatial organization. Different from an expected loss of functions, Fortaleza has strengthened its command capacities due to the new roles that the municipalities of the RMF play in the social and technical division of labor. However, these municipalities have remained dependent on the supply of services from the capital that has specialized on the tertiary sector, increasing its polarizing power and area of influence. The policies for the incentive of tourism, real estate deals, agribusiness, and the growth and expansion of the industry in Ceará have produced changes in the employment structure, on the labor market, and consequently in the metropolis. This article analyzes the impacts of the processes of restructuring in the metropolitan space of Fortaleza and their implications for the labor force profile and the spatial mobility. It shows the impulse and the rescaling of the industry in the RMF and the resulting expansion of its zone of influence to other states and the transnational space, and these processes favor the emergence of new centralities.
\end{abstract}


Key words: Productive and spatial restructuring, labor market, internal and international division of labor, mobility of the population

\section{Resumen}

Delante de la reestructuración productiva y espacial en curso, la Región Metropolitana de Fortaleza (RMF) vivencia la substitución de formas y la diversificación de sus funciones. El establecimiento de distritos industriales y viviendas tienen dado lugar a la complejidad de la estructura urbana de la metrópoli con alteraciones en el arreglo socioespacial. Fortaleza, en contraste de perder funciones, consolida su capacidad de comando, debido nuevos papeles asumidos por los municipios de la RMF en la división social y de espacio del trabajo. Sin embargo, estos municipios continuán dependiendo del abastecimiento y suprimiento de los servicios de la capital que se especializa en el terciario, aumentando su fuerza polarizadora y área de la influencia. Las políticas del incentivo al turismo, a los negocios imobilíarios, al agronegócio y la extensión de la industria del Ceará produzen transformaciones en la estructura del trabajo y, en el mercado de trabajo y, por lo tanto en la metrópoli. Este artículo analisa los impactos de la reestructuración en el espacio metropolitano de Fortaleza y sus implicaciones en el perfil de la fuerza de trabajo y en movilidad espacial. Evidencia el impulso y el redimensionamiento de la indústria en la RMF y la consecuente extensión de su zona de influencia para otros estados y espacio transnacional favoreciendo la aparición de nuevas centralidad.

Palabras clave: Reestructuración productiva y espacial, mercado de trabajo, división social y espacial del trabajo, movilidad populacional.

\section{Introdução}

Nas últimas décadas, as políticas de incentivo ao turismo e aos serviços, os negócios imobiliários, o incremento e expansão da indústria e do agronegócio no Estado do Ceará produziram mudanças na estrutura do emprego, na mobilidade espacial da força de trabalho, no mercado de trabalho como um todo e, por conseguinte, na metrópole, concentradora das riquezas e população. Isto gerou alteração na dinâmica populacional e nas formas espaciais resultantes das ações dos capitais público e privado. Por outro lado, reforçam-se os mecanismos de reprodução socioespacial dos agentes produtores do traçado urbano e a desigual forma de acesso à moradia, à rede de serviços e de infraestrutura urbana.

Este artigo analisa os impactos do processo de reestruturação produtiva sobre o espaço metropolitano de Fortaleza e suas implicações no perfil da força de trabalho e na mobilidade espacial, a partir dos anos de 1980. Evidencia-se que a reestruturação produtiva impulsionou o redimensionamento da indústria na Região Metropolitana de Fortaleza (RMF) e a consequente expansão de sua zona de influência não somente para outros municípios do Estado, mas também para o espaço transnacional, bem como favoreceu o surgimento de novas centralidades.

Inicialmente faremos uma reflexão sobre as metamorfoses na estrutura produtiva e as implicações socioespaciais. Posteriormente, enfa- 
tizaremos este impacto nos municípios de mais alto nível de integração econômica para Fortaleza, que receberam investimentos produtivos em razão da dispersão da produção, e que, com a ampliação do mercado de trabalho, apresentam maior dinâmica populacional (migração e movimento pendular). Estas transformações interferem diretamente na dinâmica socioespacial da RMF e nos permitirá apontar tendências, desafios e algumas considerações.

O estudo da Região Metropolitana de Fortaleza exige a compreensão mesmo que sucinta de sua relação com o contexto maior de reestruturação capitalista, já que os impactos na esfera do trabalho e no espaço é uma das múltiplas facetas deste processo. Para encaminhamento da pesquisa, levantamos as seguintes questões: No contexto de reestruturação produtiva, como os diferentes agentes têm participado da produção do espaço metropolitano? Qual a relação entre reestruturação produtiva, mobilidade do trabalhador, espacialização dos investimentos produtivos e dos segmentos da sociedade no espaço metropolitano? Quais são os impactos da reestruturação produtiva no mercado de trabalho e no espaço?

\section{Metamorfoses na estrutura produtiva e espacial}

A fase atual do processo de reestruturação produtiva coincide com a passagem do capitalismo industrial para o capitalismo financeiro ou monopolista. No Brasil, somente na segunda metade dos anos 1980 evidenciam-se um novo paradigma tecnológico e produtivo e uma nova organização do trabalho e do espaço.

Este processo acelera-se a partir dos anos 1990 sob o impulso das políticas neoliberais. Neste percurso, ocorre a transnacionalização do sistema capitalista de produção e um novo momento do processo de acumulação entra em vigor.

Nas últimas décadas, o governo federal brasileiro continuou com as políticas de desenvolvimento com base na intervenção planejada do Estado, iniciada nos anos 1960, e ao mesmo tempo introduziu outras ações, visando à redução dos gastos públicos e à maximização na oferta de fatores locacionais, que atraíram investimentos privados.

No contexto da guerra fiscal entre os estados, denominada por Santos e Silveira (2001) como a "guerra dos lugares", nos anos 1990 foram ampliados os incentivos para o Ceará, pautados na reestruturação do 
capital, notadamente para setores da indústria, do turismo, dos serviços e do agronegócio de exportação, com base na agricultura irrigada (fruticultura, horticultura, floricultura) e na agroindústria a ela associada.

Inaugura-se, assim, uma nova etapa de acumulação mundial do capital. Entra em cena o paradigma de acumulação capitalista contemporâneo, denominado por Harvey (1993) de "regime de acumulação flexível", por opor-se diretamente à rigidez fordista e apoiar-se "na flexibilidade dos processos de trabalho, dos mercados de trabalho, dos produtos e padrões de consumo...” (Harvey, 1993, p. 140).

Em linhas gerais, a reestruturação produtiva, calcada na produção flexível, propiciou uma reorganização do processo de gestão da produção e da força de trabalho, com novas práticas gerenciais, uma nova lógica de produção de mercadorias, o desenvolvimento de novas tecnologias e a descentralização produtiva, com a terceirização ou as relocalizações industriais. Isto ocasionou o fechamento de indústrias e abertura de outras; a modificação das regras institucionais de relacionamento entre capital e trabalho; as mudanças de hábito no consumo; as alterações nos padrões de concorrência intercapitalista etc.

Com a reestruturação produtiva, modificam-se as condições técnicas, jurídico-políticas e sociais, as formas de organização do trabalho e do processo de produção, com introdução de novas práticas gerenciais. De acordo com Ianni (1997, p. 61), “[...] desenvolvem-se novas tecnologias de produção [...] compreendendo a flexibilização do processo produtivo, ocorre todo um rearranjo da força de trabalho, envolvendo as capacidades profissionais dos trabalhadores”. Isso implicou também transformações nas relações entre capital e trabalho com a instauração de novas legislações trabalhistas de cunho flexível, adaptando-as às necessidades do capital.

Os grandes avanços científico-tecnológicos e a espetacular expansão das redes de comunicação e transporte foram condição sine qua non para a reestruturação produtiva e espacial que permitiu a dispersão mundial da produção e a criação de “espaços inteligentes”, onde a lógica capitalista pudesse fluir. Em outras palavras, está havendo, uma transnacionalização que alcança espaços até então não penetrados pelo capital (Santos, 1996).

Ocorrem inovações tecnológicas no processo produtivo, cuja expressão tem sido "a microeletrônica, a automação, a robótica, a informática e as redes que aceleram e multiplicam a capacidade produtiva da força de trabalho" (Ianni, 1997, p. 157). 
Os novos padrões de gestão/organização do trabalho, que têm assumido importância decisiva na flexibilização das relações de trabalho, advêm de forma mais intensa no setor industrial. Juntamente com as inovações tecnológicas, observa-se a introdução de procedimentos organizacionais globais (kaban, just in time); uma série de racionalizações da produção (downsizing e a reengenharia), e a introdução de programas de qualidade total que possibilitam o gerenciamento do trabalho via círculos de controle de qualidade, gestão participativa; um melhor aproveitamento do espaço e redução do tempo de produção; melhor controle da qualidade do produto e maior produtividade. Valoriza-se a cooperação, o trabalho em equipe, a polivalência e a multifuncionalidade do trabalhador.

É neste contexto que a RMF, na busca de alcançar um padrão de competitividade mais elevado, passa a efetivar consideráveis alterações na sua estrutura organizacional de produção e nas relações sociais de produção e trabalho que acarretam, sobretudo, modificações na sua dinâmica espacial.

Capital, trabalho e dinâmica socioespacial na Região Metropolitana de Fortaleza

Instituída através da Lei Complementar $n^{\circ}$ 14, de 6 de junho de 1973, que criou as primeiras regiões metropolitanas no Brasil, a Região Metropolitana de Fortaleza (RMF), inicialmente constituída pelos municípios de Fortaleza, Caucaia, Maranguape, Pacatuba e Aquiraz, totaliza, hoje, 15 municípios, quais sejam: Fortaleza, Caucaia, Maranguape, Pacatuba, Aquiraz, Maracanaú, Eusébio, Guaiúba, Itaitinga, Chorozinho, Pacajus, Horizonte, São Gonçalo do Amarante, Pindoretama e Cascavel. Conforme Silva (2009, p. 15), a "institucionalização deu-se antes que o processo de metropolização se manifestasse”.

Segundo dados do IBGE (2010), com 3.559.398 habitantes e uma área de 5.785,822 km², a RMF apresenta grande concentração populacional na capital. Fortaleza continua apresentando um elevado contingente populacional (2.447.409 habitantes), ratificando seu processo de crescimento, notadamente macrocefálico. Caucaia tem a segunda maior área da RMF $\left(1.227,895 \mathrm{~km}^{2}\right)$ e também a segunda posição no quantitativo populacional (324.738 habitantes). Isto se deve dentre outras coisas ao "alto nível de integração à metrópole, em virtude da política de construção de conjuntos habitacionais, nos idos anos 1980, para responder ao déficit 
habitacional em Fortaleza, e mais recentemente com a transformação de antigos espaços de veraneio em locais de primeira residência, aumentando, consequentemente, o fluxo entre Caucaia e Fortaleza”.

Maracanaú com 209.748 habitantes é o terceiro município em população e o segundo em densidade populacional da RMF, apresentando alto nível de integração, em razão da presença do distrito industrial e de vários conjuntos habitacionais, construídos para alojar os trabalhadores das indústrias implantadas;

[...] o déficit habitacional na capital acaba por impor transferência de população para Maracanaú em níveis maiores que a indústria que a motivou, gerando movimentos pendulares representativos do aumento gradativo da integração do município à dinâmica da aglomeração. (Dantas; Silva, 2009, p. 31)

A elevada concentração populacional proporciona em um primeiro momento vantagens, como economias de aglomeração, dada a concentração de produtos, serviços e mercado consumidor, e uma maior pressão junto ao poder público por infraestrutura e saneamento básico. No entanto, esta concentração torna-se deseconomia, apresentando inúmeras desvantagens, como o agravamento das desigualdades socioespaciais, a poluição, a criminalidade, o desemprego, a vulnerabilidade socioambiental, o descompasso entre oferta e procura de serviços (transporte, habitação, segurança, saúde, educação, saneamento e lazer) etc. O Estado, como um dos agentes produtores do espaço urbano, agrava ainda mais o processo de concentração de renda ao aplicar recursos em benefício de setores ou atividades privadas, em detrimento dos investimentos públicos.

Fortaleza é o principal ponto de escoamento da produção e de convergência de fluxos que se difundem para diferentes espaços. A presença de redes direcionadas para o município-polo, e deste para locais cada vez mais longínquos, propiciou a Fortaleza o papel de comando, construído ao longo da ocupação do espaço cearense. Esta centralidade pode ser evidenciada pela concentração de capitais, serviços, equipamentos urbanos, profissionais qualificados e sistemas técnicos.

Para isso, concorrem os "sistemas técnicos" (Santos, 1994, 1996) de transportes e comunicações (infovias: cabos de fibra óptica, telefonia, rede mundial de computadores etc.).

Estradas estaduais e federais cortam e integram a RMF, facilitando os fluxos de matéria-prima, produtos e população entre áreas de diversidade 
natural (litoral, serra e sertão), social (bairros de classe média, bairros operários, condomínios fechados, conjuntos habitacionais) e atividades econômicas (espaços de lazer, turismo, indústria, comércio, serviços etc.).

Com uma infraestrutura rodoferroviária, aeroportuária e a privilegiada posição geográfica que reúne para colocar os produtos em poucos dias nos mercados da Europa, dos Estados Unidos e do Mercosul, Fortaleza insere-se no mapa da nova geografia mundial.

A produção do espaço da circulação, com a expansão do "meio técnico-científico-informacional" (Santos, 1996) sustentáculo do processo de reestruturação produtiva, se faz presente na RMF para atender diversos fins, muitos deles exteriores às demandas da população local.

A integração da economia mundial, graças ao desenvolvimento dos meios de transportes, à troca contínua de informações que se dá em tempo real e à "unicidade técnica" (Santos, 1994, 1996), possibilitou um novo patamar de flexibilidade e integração. A mais rápida circulação planetária dos fluxos de trocas significou uma mobilidade maior de capital, tecnologia e força de trabalho e uma dispersão geográfica da produção. Este fato promoveu especializações regionais e a integração dos espaços produtivos em redes de produção globais. Segundo Araújo (2000), ocorre a simultaneidade da fragmentação (fabricação, distribuição e comercialização) e integração (espaços não autossuficientes) com a regulação final do processo produtivo.

A reestruturação produtiva e sua consequente expansão para os espaços periféricos de Fortaleza com a implantação de "fixos e fluxos" (Santos, 1988) acarretam novas formas tecnológicas, organizacionais e ocupacionais e uma maior mobilidade da força de trabalho, dada a fluidez dos sistemas de transportes e comunicações, o que interfere diretamente na estrutura socioespacial da RMF.

Com o impulso ao turismo, ao agronegócio e às modernas indústrias implantadas nos demais municípios da RMF, ocorre a intensificação dos fluxos de pessoas que procuram se inserir no mercado de trabalho, além dos fluxos de mercadorias e informações. Estes fluxos interligam o mercado nacional e transnacional, passando a RMF a ocupar novo papel na divisão interna e internacional do trabalho.

Dessa forma, o processo de reestruturação produtiva ocasiona um reordenamento nas forças produtivas, nas relações de trabalho e, notadamente, no espaço. A RMF, ao se inserir no processo de transformações globais, passa por uma redefinição e refuncionalização do seu espaço com 
importante expansão dos "sistemas de objetos e de ação", dando-lhe mais fluidez (Santos, 1988, 1996).

Segundo dados do IPECE, dos dez municípios com maior PIB estadual em 2007, destacam-se Fortaleza $\left(1^{\circ}\right)$, Maracanaú $\left(2^{\circ}\right)$, Caucaia $\left(4^{\circ}\right)$, Eusébio $\left(6^{\circ}\right)$, Horizonte $\left(7^{\circ}\right)$, Maranguape $\left(8^{\circ}\right)$ e São Gonçalo do Amarante $\left(9^{\circ}\right)$, pertencentes à RMF. Entre os de maior PIB per capita, estão Eusébio $\left(1^{\circ}\right)$, São Gonçalo do Amarante $\left(2^{\circ}\right)$, Maracanaú $\left(3^{\circ}\right)$, Horizonte $\left(4^{\circ}\right)$, Fortaleza $\left(5^{\circ}\right)$ e Pacajus $\left(10^{\circ}\right)$. Representando $65 \%$ do PIB estadual, a RMF tem, na capital, a maior representatividade do PIB metropolitano. Fortaleza, além da concentração demográfica, centraliza os investimentos da RMF, mesmo com a extensão do tecido urbano e o processo de descentralização que acompanha a lógica global.

No que se refere às atividades produtivas na RMF, Eusébio $(62,1 \%)$, Horizonte (57,6\%), Maracanaú (57,9\%) e Pacatuba (49,6\%) apresentaram o PIB industrial maior que o do Ceará $(23,6 \%)$ e foram superiores também no PIB dos setores agropecuário e de serviços. Os municípios que apresentaram menor representatividade no setor industrial, inclusive com PIB industrial menor que o estadual, foram Pindoretama, Chorozinho e Guaiúba.

Fortaleza é o maior município em representatividade no setor de serviços (79,6\%), o segundo menor no setor agropecuário $(0,2 \%)$, e o décimo primeiro no setor industrial (20,3\%).

Fortaleza, que tinha primordialmente papel administrativo, comercial e de prestadora de serviços, com o crescimento industrial amplia suas funções. Ressalta-se a capital que até a década de 1970 contava com maior concentração industrial. As indústrias localizadas ao longo da avenida Francisco Sá e próximo da via férrea atraíram grande contingente de migrantes para os bairros vizinhos, que se fixaram de forma desordenada, contribuindo para a expansão da cidade de Fortaleza sem um adequado planejamento.

Os fatores que propiciaram a concentração industrial na zona oeste de Fortaleza deixam de ser importantes, diante da atuação planejada do Estado através da SUDENE, que ofereceu incentivos fiscais e financeiros para implantação de indústrias na RMF.

O resultado desta política foi a concentração de indústrias da RMF no Distrito Industrial de Maracanaú, instalado nos anos 1980, concorrendo para atração de trabalhadores na busca de inserção no mercado de trabalho. Paralelo a esta, outra política voltada para habitação popular, favorece 
a construção, no seu território, de conjuntos habitacionais construídos através do Sistema Financeiro da Habitação. Atualmente, Maracanaú tem o segundo PIB da RMF e está em terceiro lugar, em população.

Dentre as grandes indústrias localizadas em Maracanaú, destacamse Colonial Indústria de Bebidas Ltda., Têxtil União S/A, Vicunha Têxtil S/A, Tintas Hidracor S/A, Gerdau Aços Longos S/A, Esmaltec S/A, CocaCola (NORSA Refrigerantes Ltda.), Fábrica Estrela e Avon Cosméticos.

Nos anos de 1990, além de Maracanaú, outros eixos industriais consolidam-se ao longo da rodovia BR-116, nos municípios de Horizonte e Pacajus. Temos também a expansão do eixo industrial para o município de Eusébio. Com a criação do complexo industrial e portuário do Pecém, em 2002, onde serão instaladas uma siderúrgica e a refinaria de petróleo Premium II da Petrobrás, sai fortalecido o eixo industrial Caucaia-São Gonçalo do Amarante, redefinindo-se o papel até então exercido por estes municípios na estrutura socioespacial metropolitana. Ademais, com a criação da Zona de Processamento de Exportações - ZPE, incentivos fiscais serão direcionados para atividade industrial, que representavam em 2007, 19,6\% do PIB municipal, e impulsionará também o setor de serviços. Isto traz inúmeras consequências para a dinâmica do mercado de trabalho, a mobilidade da população e o crescimento de fixos e fluxos, estreitando as relações deste município com Caucaia e a capital e ampliando a demanda pelo solo urbano.

Para Amora (2005, p. 376) "a distribuição espacial da indústria constitui fator significativo da metropolização e reforça a preponderância da cidade de Fortaleza, que se projeta nacionalmente”. A descentralização industrial para outros municípios da RMF será acompanhada da intensificação de um mercado de trabalho urbano e uma mudança frente aos novos padrões de produção e consumo.

De acordo com os dados do Guia Industrial do Ceará (2010), há preferência das indústrias modernas pelos municípios periféricos da RMF, permanecendo em Fortaleza o maior quantitativo das indústrias tradicionais.

A política de interiorização e descentralização industrial garantiu a redução de $45 \%$ do pagamento do ICMs pelas indústrias localizadas na RMF e 75\% para as implantadas em municípios mais distantes. Isto favoreceu a redistribuição no espaço, com fábricas instaladas na RMF e em outros municípios brasileiros. Dentre as quais, citamos: Dakota Nordeste S/A (Maranguape e Russas), Grendene S/A (Fortaleza, Crato e Sobral e setor 
administrativo financeiro no Rio Grande do Sul), Moinho Dias Branco S/A (Eusébio e Crato), Indaiá Brasil Águas Minerais Ltda. (Fortaleza, Guaramiranga e Crato), e a transnacional Coca-Cola (Maracanaú-CE, Bahia, Piauí e Rio Grande do Norte).

A interiorização industrial no Estado do Ceará implicou alteração da direção dos fluxos migratórios que deixam de ser somente do tipo campocidade e passam a ser predominantemente urbano-urbano (Muniz, 2004).

$\mathrm{Na}$ política de integração nacional, o estado investia no desenvolvimento industrial visando sustar o movimento migratório, pois se acreditava que a indústria absorveria parte do contingente populacional vindo do campo. Hoje, com a política de interiorização industrial ocorre a "migração descendente" (Santos, 1993), ou seja, migração da cidade para o campo. Conforme Muniz (2004), esta migração ocorre notadamente por parte do trabalhador com maior qualificação, embora a migração ascendente (do campo para cidade) ainda continue, dentre outras coisas, devido à busca pela empregabilidade, notadamente nos períodos de entressafra que exigem menos trabalho braçal.

Os períodos de redução da produção industrial e agroindustrial no meio rural também ocasionam a unificação do mercado de trabalho urbano-rural na cidade com a presença do agrícola não rural (Santos, 1988) em atividades da indústria de construção civil ou em outras atividades que exijam uma menor qualificação. Diante da complexidade e heterogeneidade da "classe-que-vive-do-trabalho" (Antunes, 1998) temos ainda os que se inserem na geração de empregos indiretos ligados à atividade agrícola, como a terceirização do transporte de trabalhadores e produtos, e dos serviços em geral (alimentação, limpeza e higiene, administração, recrutamento de trabalhadores temporários, assistência médica e educacional ao trabalhador).

O deslocamento cidade-campo vem acompanhado da mobilidade espacial de trabalhadores entre municípios com maior vocação industrial (Fortaleza, Caucaia, Maracanaú, Pacajus, Horizonte e brevemente São Gonçalo do Amarante) e turística (Aquiraz, Caucaia), em decorrência da redistribuição destas atividades em outros municípios da RMF.

Esta mobilidade se caracteriza em movimento pendular dada a proximidade e o crescente investimento nos sistemas técnicos voltados às comunicações e aos transportes. A melhoria do sistema viário na RMF (BRs e CEs e vias municipais) permite acesso mais rápido, encurtando, portanto, o tempo que separa os espaços de moradia, trabalho e lazer. 
O desenvolvimento do capitalismo é contraditório e desigual, promovendo o deslocamento de trabalhadores da zona rural dos municípios mais distantes para suas sedes. Como o sistema de transporte intraurbano nestas localidades é deficiente, a tendência é o trabalhador se estabelecer em espaços mais próximos ao local de trabalho. Isto encurta o tempo que separa espaço de moradia e de trabalho, ocasionando a redução da população rural nestes municípios e impulsionando o modo de vida urbano. Ou seja, ocorre uma mudança não somente na forma (organização espacial) e função dos municípios da RMF, mas, também, mudanças qualitativas que se referem à subjetividade e modo de vida, como consequência das novas práticas sociais e aceleração do tempo.

\section{Considerações finais}

Diante do exposto, podemos afirmar que a reestruturação do capital tem trazido mudanças na estrutura produtiva da RMF, não se restringindo a aspectos técnicos e econômicos da produção, envolvendo notadamente os aspectos sociais e espaciais.

Além da mudança de gestão no espaço metropolitano, podemos citar, dentre as consequências da reestruturação capitalista, a modernização e o redimensionamento da indústria no espaço e o consequente movimento do capital financeiro especulativo com a expansão da economia de Fortaleza para o espaço metropolitano, bem como a ampliação de sua zona de influência não somente para outros municípios do Estado, mas também para o espaço transnacional. É um processo concomitante de desconcentração, expansão e formação de novas centralidades.

Ademais, o estabelecimento de distritos industriais e de conjuntos habitacionais tem propiciado uma complexa estrutura urbana, com alterações no arranjo socioespacial metropolitano, novas dinâmicas intraurbanas e nas relações entre as cidades.

Embora os impactos decorrentes da incorporação de novos municípios apresentem forte efeito político-administrativo, o núcleo dos fluxos ainda é a capital, detentora de melhores condições de mobilidade e acessibilidade aos serviços e às redes de infraestrutura. Soma-se a isto o conjunto de inovações ligadas à atividade produtiva e à concentração da mão de obra qualificada que se fixa em Fortaleza.

Se atentarmos para o fato de que a industrialização na zona oeste impulsionou o fluxo migratório do campo para Fortaleza, hoje, o aumento 
da zona de influência da capital, o processo de expansão industrial e o incentivo ao turismo aumentam o fluxo demográfico para outros municípios da RMF, sem um adequado planejamento e uma oferta de moradias, infraestrutura e serviços urbanos, gerando inúmeros problemas urbanos.

Com o incentivo às diversas outras atividades ligadas ao setor terciário e o incremento dos setores secundário e primário no Ceará, Fortaleza amplia suas funções. Ao mesmo tempo em que há continuidade da participação do emprego industrial, ampliam-se os empregos formais em outros setores e cresce a informalidade no comércio e serviços. Fortaleza não se firma como polo industrial, mas avança como cidade do terciário, com a prestação de serviços (educação e saúde) e atividades principalmente voltadas para o setor secundário e também para o turismo, mercado imobiliário e agronegócio, atendendo a demandas espaciais que ultrapassam as fronteiras do Ceará e do Nordeste.

\section{Referências}

ALVES, Giovanni. O novo (e precário) mundo do trabalho. São Paulo: Boitempo, 2000.

AMORA, Zenilde Baima. Indústria e espaço no Ceará. In: SILVA, José Borzacchiello da Silva; CAVALCANTE, Tércia Correia; DANTAS, Eustógio Wanderley Correia; SOUSA, Maria Salete de et al. Ceará: um novo olhar geográfico. Fortaleza: Edições Demócrito Rocha, 2005.

ANTUNES, Ricardo. Adeus ao trabalho? Ensaio sobre as metamorfoses e a centralidade do mundo do trabalho. Campinas: Cortez/Ed. Unicamp, 1998.

ARAUJO, Tânia Bacelar. Ensaios sobre o desenvolvimento brasileiro: heranças e urgências. Rio de Janeiro: Revan/Fase, 2000.

BENKO, Georges. Economia espaço e globalização na aurora do século XXI. São Paulo: Hucitec, 1999.

CHESNAIS, François. A mundialização do capital. São Paulo: Xamã, 1996.

DANTAS, Eustógio Wanderley Correia, SILVA, José Borzacchiello da, COSTA, Maria Clélia Lustosa. Da cidade à metrópole: (trans)formações urbanas em Fortaleza. Fortaleza: Edições UFC, 2009.

DANTAS, Eustógio Wanderley Correia; SILVA, José Borzacchiello da. A Formação Histórica da Metrópole e principais Tendências de Desenvolvimento. In: PEQUENO, Luis Renato Bezerra (Org.). Como anda Fortaleza? Rio de Janeiro: Letra Capital Observatório das Metrópoles, 2009.

HARVEY, David. Condição pós-modema. São Paulo: Loyola, 1993.

IANNI, Octavio. A era do globalismo. 3. ed. Rio de Janeiro: Civilização Brasileira, 1997. 
MUNIZ, Alexsandra M. Vieira. Reestruturação produtiva e trabalho agrícola no Baixo Jaguaribe. Dissertação (Mestrado) - Universidade Federal do Ceará, Fortaleza, 2004.

SANTOS, Milton. Metamorfose do espaço habitado. São Paulo: Hucitec, 1988.

SANTOS, Milton. Técnica, espaço, tempo. Globalização e meio técnico-científicoinformacional. São Paulo: Hucitec, 1994.

SANTOS, Milton. A natureza do espaço: técnica e tempo. Razão e emoção. São Paulo: Hucitec, 1996.

SANTOS, Milton. O retorno do Território. In: SANTOS, Milton; SOUZA, M. Adélia; SILVEIRA, M. Laura. Território, globalização e fragmentação. 5. ed. São Paulo: Hucitec/Anpur, 1998.

SANTOS, Milton; SILVEIRA, Maria Laura. O Brasil: território e sociedade no início do século XXI. 9. ed. Rio de Janeiro: Record, 2001.

SILVA, José Borzacchiello da. Características gerais da Região Metropolitana de Fortaleza. DANTAS, Eustógio Wanderley Correia; COSTA, Maria Clélia Lustosa (Orgs.). Vulnerabilidade socioambiental na Região Metropolitana de Fortaleza. Fortaleza: Edições UFC, 2009.

Alexsandra Maria Vieira Muniz - Professora Assistente do Departamento de Geografia da Universidade Federal do Ceará. Doutoranda em Geografia pela Universidade Federal do Ceará.

José Borzacchiello da Silva - Professor Titular da Universidade Federal do Ceará. Mestre e Doutor em Geografia Humana pela USP. Pós-doutoramento em Geografia Humana pela Université de Paris IV - Sorbonne.

Maria Clélia Lustosa Costa- Professora Adjunta IV do Departamento de Geografia da Universidade Federal do Ceará. Mestre em geografia pela USP. Doutoranda em Geografia na Université Paris III. 